\title{
Wetting of Mineral Surfaces by Fatty-Acid-Laden Oil and Brine: Carbonate Effect at Elevated Temperature
}

\author{
Martin E. J. Haagh, ${ }^{\circ}$ Nathalie Schilderink, Frieder Mugele, and Michel H. G. Duits*(i) \\ Physics of Complex Fluids Group and MESA+ Institute, Faculty of Science and Technology, University of Twente, PO Box 217, \\ 7500 AE Enschede The Netherlands \\ Supporting Information
}

\begin{abstract}
Oil recovery yields from sandstone reservoirs strongly depend on the wetting properties of the rock. Carboxylic acids present in crude oil may decrease the water wettability by adsorbing onto the mineral surface via cation interactions. A highly simplified version of this scenario has been mimicked in the lab to study these mechanisms in more detail. In previous studies on oil/brine/mineral systems the formation of fatty acid monolayers on mica was observed, yielding water contact angles in ambient oil of up to $60^{\circ}$. Here we demonstrate that the presence of $2 \mathrm{mM}$ bicarbonate (typical for brines) has a strong influence at temperatures above $40{ }^{\circ} \mathrm{C}$ (as in reservoirs), yielding water contact angles in ambient oil up to $160^{\circ}$. Similar behavior was found for a variety of carboxylic acids. On increasing the (even) carbon number of simple fatty acids from 8 to 20 , the contact angle becomes larger until it saturates at 16 carbon atoms. Similar hydrophobic layers are formed by pulling a sheet of mica through an oil/water interface at comparable velocities. By studying the nanometer-scale topography and chemistry of these dip-coated samples, we can infer that the adsorbed layer is composed of alternating carboxylic acid bilayers that are held together by a very thin intermediate layer containing calcium and (bi)carbonate ions. Exposure to low-salinity water makes the multilayers disappear and the mineral surface become water-wet again, demonstrating that the presence of these structures can lead to a strong salinity-dependent wettability alteration.
\end{abstract}

\section{INTRODUCTION}

Oil recovery from sandstone reservoirs by seawater flooding, also known as secondary water flooding, is an inefficient process, as typically $60-80 \%$ of the oil is left in the reservoir at the end of its economic lifetime. ${ }^{1}$ Significant improvements in oil recovery have been achieved by a tertiary low-salinity water flooding (LSWF). ${ }^{2,3}$ Yet in spite of many core flooding experiments it remains challenging to predict how much incremental oil can be obtained from a given reservoir using a certain flooding water composition. The reasons for this are manifold. Inherently, experiments on rock cores are not well suited to identify the pore- and mineral-scale mechanisms underlying the LSWF effect due to the difficult (optical) access. ${ }^{4}$ Also, the complexity of the system in which oil release takes place plays a major role. Rock, oil, and brine typically have rich compositions, leading to a variety of (competing) interactions. In addition, significant variations occur in geometry, oil/brine/rock chemistry, and thermodynamic parameters within and between experiments. Because of these experimental and interpretive hurdles, conclusive evidence of how LSWF works cannot be provided by core flooding experiments alone. It is often claimed that under lowsalinity water flooding microscopic water films at the rock surface expand due to increasing electric double-layer forces. This view is however not backed up by all core flooding data, which often point to a more cation-specific rather than ionic strength-driven effect. ${ }^{5,6}$ On the basis of such experiments, it was possible to conclude that an improved water wettability of the sandstone is a key element of the low-salinity effect. ${ }^{5-7}$ However, the details of this wettability alteration remain elusive.
A more comprehensive understanding of the low-salinity effect could be obtained from direct observations of either the wettability alteration or changes in the (chemistry of) microscopic films covering the rock. Each of these approaches still requires circumvention of problems: the lack of optical access to the rock in the former case and the overwhelming chemical complexity of the fluids (in particular the oil) in the latter case. The challenge therefore lies in finding a model system that in spite of its simplified nature can still capture the key elements which govern the wettability aspects. In the current work, we attempted to achieve this by using brines and oils with simplified compositions and well-defined smooth mineral substrates. Although sandstone rock often presents a mixed mineral surface, the focus in this work will be on pure mica to represent the adsorbed clay components. We combine macroscopic contact angle measurements with microscopic characterizations of modified mineral surfaces and examine the link between the behaviors at these two length scales.

Several previous works followed this approach by studying the wetting of model mineral (mica and silica) substrates by droplets of simplified brine (1-4 dissolved salts) in an ambient of stearic acid-laden alkane oil at room temperature. In these model systems the wettability was found to depend strongly on the divalent cation concentration ${ }^{8}$ and hardly on the ionic strength. ${ }^{9}$ The key role of the divalent cations was linked to their well-known tendency to bind to carboxylate groups, thereby forming organometallic complexes. ${ }^{10}$ Such (positively

Received: April 29, 2019

Revised: September 17, 2019

Published: September 20, 2019 
charged) complexes are known to adsorb on negatively charged solid/brine interfaces: ${ }^{11,12}$ a behavior that was confirmed in wetting experiments with brine droplets on the mica and silica substrates. ${ }^{13}$ Here, organic monolayers of (calcium) stearate were found around the contact line of droplets that contained $\mathrm{Ca}^{2+} .8,13$ Flushing such droplets with calcium-depleted brines led to removal of the adsorbed layers, ${ }^{9,14}$ thereby revealing the reversible nature of the layer formation. Taking these various findings together, it appears that these model systems-in spite of their simplicity-are able to reproduce the key elements of wettability alteration via LSWF: the presence of an initial adsorbed organic layer, which showed an increased water wettability on exposure to "lowsalinity" water.

However, the existing studies on this model system are still hampered by significant shortcomings. One of them is that the far majority of experiments was done at room temperature (RT). It is important to study the effects of salinity on wettability also at elevated temperatures, since reservoir temperatures at intermediate depths typically range from 50 to $120{ }^{\circ} \mathrm{C} .{ }^{15}$ This recently prompted us to perform a first study on layer formation by fatty acids (using simple brines and oils) at temperatures up to $60{ }^{\circ} \mathrm{C} .{ }^{14}$ In that work the divalent cation concentration was found to remain important for wettability. Additionally, for $T \geq 50{ }^{\circ} \mathrm{C}$ a remarkable increase in water contact angle (from $30^{\circ}$ to $>120^{\circ}$ ) was observed, suggesting a change in the structure and/or composition of the adsorbing organometallic layer. This drastic effect required the additional presence of bicarbonate ions (at low concentrations as in seawater). The origin of this synergistic effect of bicarbonate ions and elevated temperature has however remained unclear. The presence of carbonate species is known to have an effect on low-salinity water flooding in sandstone cores, which is typically ascribed to its effect on $\mathrm{pH}^{16-18}$ However, in the simplified system the $\mathrm{pH}$ was not altered, so the dramatic wettability alteration must have been caused by another effect, such as complexation of the carbonate species with the fatty acids. Such interactions are known from research into oil recovery from carbonate reservoirs ${ }^{19,20}$ but not yet investigated for sandstone-like systems. From biomineralization literature it is known that at room temperature templated growth of $\mathrm{CaCO}_{3}$ on carboxylate-terminated monolayers is common ${ }^{21,22}$ and that in this manner composite layers of fatty acids and $\mathrm{CaCO}_{3}$ can form. ${ }^{23}$ However, in wetting studies at room temperature, adding carbonate ions to the brine did not produce the strong wettability alteration. Hence, it remains to be elucidated what type of hydrophobic layer gets formed and how.

Another shortcoming of the model systems used so far is the oversimplified oil composition. Crude oils are well known to contain a large number of components, including several classes of compounds which show surface activity: acidic, basic, and aromatic ones. Even restricting to the acidic compounds, a range of carboxylic acids remains to be considered: saturated/ unsaturated, aromatic, linear/branched. Changes in the molecular architecture of the hydrophobic chain could change the adsorption and self-assembly at the mineral/brine interface (and similarly for mixtures of carboxylic acids). Such effects have been studied for layers formed at brine/air interfaces ${ }^{24,25}$ but not systematically for carboxylic acids deposited directly on solid substrates by a moving contact line in a brine/oil/mineral system. While these variations in oil composition will still be a modest step toward the complexity of crude oil, they should contribute to a better understanding of how specific features of molecular architecture affect their interactions.

In the present paper we improve the model system along both lines (elevated temperature and enhanced oil complexity) and examine the ensuing changes in physicochemical behavior. Using contact angle measurements we study the effect of bicarbonate in brine droplets (in ambient oil with palmitic acid) on the wettability of mica and silica at temperatures up to $60{ }^{\circ} \mathrm{C}$. Additionally, to examine the influence of the oildissolved molecules on the wetting properties, we explored several other carboxylic acids at high temperature. To better understand how the macroscopic wetting originates from the chemical and topographical structure at the microscale, we complement the contact angle measurements on brine drops with a microscopic imaging of the layers left behind by them using atomic force microscopy (AFM). Additionally, we examine layers formed under a better control over the contact line velocity via experiments where the mineral substrates are pulled across the brine/oil contact line.

\section{MATERIALS AND METHODS}

All chemicals are reaction grade and purchased from Sigma. As oil phase we used $n$-decane, purified by flushing it $5 \times$ through a $5 \mathrm{~cm}$ column of aluminum oxide powder, removing most surface active impurities (verified by the surface tension decreasing $<0.1 \mathrm{mN} / \mathrm{m}$ per hour after treatment). ${ }^{26} \mathrm{~A}$ single type of carboxylic acid $(\mathrm{C} 6=$ hexanoic acid, C8, C10, C12, C13, C14, C15, C16, C17, C18, C20, oleic acid, or 12-phenyl dodecanoic acid) was then dissolved in it at concentrations of $0.1 \mathrm{mM}$ (equivalent to a total acid number of 7.9 $\mathrm{mg} \mathrm{KOH} / \mathrm{g}$ ), $1 \mathrm{mM}$, or $10 \mathrm{mM}$. The brine phase was made by dissolving $10 \mathrm{mM} \mathrm{CaCl}$ and $2 \mathrm{mM} \mathrm{NaHCO}_{3}$ in deionized water (Millipore, resistivity $18.2 \mathrm{M} \Omega \mathrm{cm}$ ), similar to their concentrations in seawater. It was then brought to the $\mathrm{pH}$ of choice at room temperature by adding small amounts of $0.1 \mathrm{M} \mathrm{NaOH}$ or $\mathrm{HCl}$. As solid substrate we used sheets of the mica mineral muscovite (B \& M Mica Co., Inc.) or amorphous silica in the form of fused quartz (SPI Supplies). Clean mica surfaces were prepared by cleaving them right before submerging them in the oil, which results in an atomically smooth surface on a scale of hundreds of micrometers. ${ }^{27}$ Quartz substrates were cleaned by sonicating them for $10 \mathrm{~min}$ in a detergent solution (Mucasol, Sigma-Aldrich), then in deionized water, and last in an ethanol and isopropanol 1:1 mixture. The sheets were then dried with nitrogen and cleaned in a UV ozone cleaner (BioForce Nanosciences, Inc.) for $15 \mathrm{~min}$.

Contact angles were measured from the water phase using a contact angle goniometer (Dataphysics OCA 20L, schematically shown in Figure 1A, more elaborately in SI Figure S1) with a droplet dispensing unit. The steel needle of the latter was filled with brine solution at RT $\left(20 \pm 1{ }^{\circ} \mathrm{C}\right)$ and immersed in a glass cuvette (Hellma Analytics) filled with oil at the measurement temperature. After a dwell time of $1 \mathrm{~min}$ to allow thermal equilibration, the experiment was started by depositing a $2 \mu \mathrm{L}$ drop on the sample sheet. For elevated temperature measurements the cuvette was fitted with a copper casing and placed inside a windowed temperature control chamber (Dataphysics TFC 100Pro) which was heated from below by circulating water. The temperature was verified by a mercury thermometer in the oil. Due to the spontaneous evolution of the droplet shape (see below), advancing or receding contact angles could not be measured. Instead, we report (besides some transient data) the final contact angle of the droplet, i.e. after it had stopped receding. For each condition, final contact angles were measured and averaged over 20 separate droplets with typically $3-5$ droplets per pristine substrate placed a few millimeters apart to prevent interaction.

Additional water contact angle measurements (in the same setup) were performed while the droplet composition was changed using a (mechanically gentle) fluid exchange technique which was earlier demonstrated. ${ }^{9,14}$ Briefly, $20 \mu \mathrm{L}$ droplets were deposited by hand 


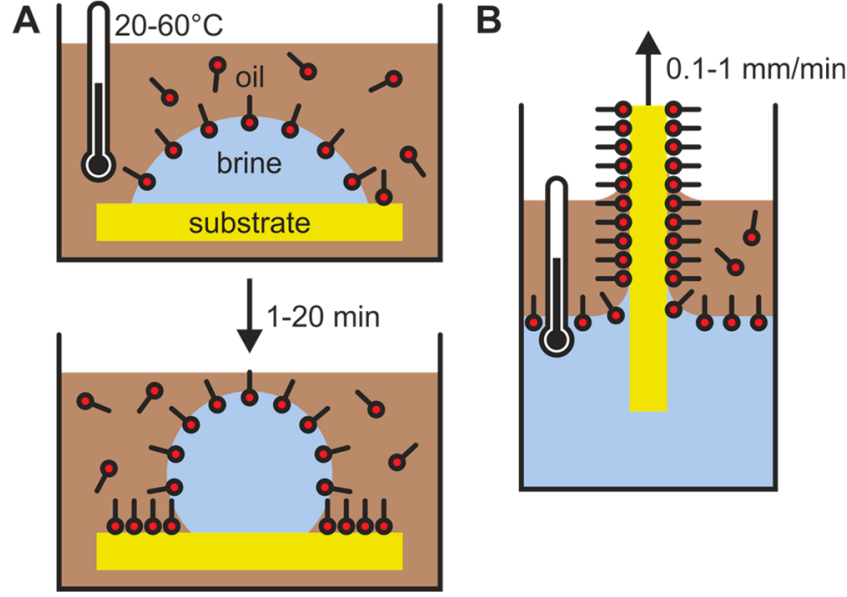

Figure 1. Schematics of setups for contact angle measurements (A) and dip coating (B).

using a pipet at $60{ }^{\circ} \mathrm{C}$. After the droplet had reached the final contact angle, two capillaries (100/170 $\mu \mathrm{m}$ inner/outer diameter, VitroCom) connected to a push-pull syringe pump (Legato, KD Scientific) were inserted to exchange the brine with deionized water at $20 \mu \mathrm{L} / \mathrm{min}$ while keeping the droplet volume constant. The outlet needle was positioned close to the substrate to extract the initial high-salinity phase preferentially. Since some mixing between the defending and the invading liquids still takes place, the droplet volume was exchanged about 20 times.

Besides these droplet deposition experiments we also exposed substrates to a forced moving contact line (Figure 1B). The aim of the latter was to get a more homogeneous distribution of the deposited layers. These experiments were carried out in a heated water bath. After thermal equilibration of the brine and oil in separate vials (in the same bath) for $30 \mathrm{~min}$ the oil was carefully added to the brine. Hereafter the substrate slide was immersed, and the experiment started within $5 \mathrm{~min}$. The substrate was pulled, at constant speed, through the oil/brine interface by a clamp attached to a motorized travel stage (Thorlabs).

After the droplet deposition or dip-coating experiment, the sheet was taken out of the oil and residual oil and water were blown off with nitrogen, such that no visible liquid remained on the substrate. Next, these sheets were dried with nitrogen and kept in a nitrogen atmosphere until they were analyzed. AFM imaging was performed using amplitude modulation (20 nm amplitude, set point at $18 \mathrm{~nm}$ ) in air using NSC36 cantilevers (MikroMasch) in a Bruker Dimension Icon. SEM imaging was done using a Zeiss MERLIN HR-SEM. XPS measurements were performed using a PHI Quantera SXM. Confocal Raman spectroscopy was performed using a Witec alpha300 R, where each spectrum was averaged over 1500 accumulations at the same location with an integration time of $1 \mathrm{~s}$ per accumulation.

Bulk speciation of the ions dissolved in the brine was determined using Visual MINTEQ 3.1, which performs equilibrium calculations using a database with all common equilibrium reaction constants for variable temperatures. To be consistent with our experimental procedure we first calculated the amount of strong acid/base needed to reach the experimental $\mathrm{pH}$ as set at $20^{\circ} \mathrm{C}$. Then while keeping this composition fixed we calculated the equilibrium speciation at varying temperatures. Equilibration with $\mathrm{CO}_{2}$ from the air was not taken into account, since we suppressed this in the experiments by not letting the brine phase age and measuring under oil (see above). In most calculations also precipitation was not taken into account. The exception was the $\mathrm{pH}$, which was calculated both with and without $\mathrm{CaCO}_{3}$ precipitation allowed for comparative purposes. Further justification for neglecting $\mathrm{CO}_{2}$ equilibration and precipitation was obtained from aging experiments (discussed in the SI, Figure S9), which showed no visible precipitation and negligible $\mathrm{pH}$ change during the time scale of our experiments.

\section{RESULTS}

To examine the wetting behavior we placed droplets of brine onto mica sheets submerged in $n$-decane containing palmitic acid (C16) and measured water contact angles. A universal behavior was observed: regardless of the explored temperature, $\mathrm{pH}$, and liquid composition, the drops spread to contact angles of $\sim 10^{\circ}$ in about $1 \mathrm{~s}$ and then retracted to higher contact angles over the course of 1-20 min. This "self-hydrophobizing" phenomenon, also termed "autophobing", 28 has been described in detail for similar oil/brine/mineral systems at room temperature. ${ }^{8}$ It arises when amphiphilic molecules (here organometallic complexes) are formed at the brine/oil interface, get transported along that interface, and subsequently get deposited on the solid by the three-phase contact line. The retracting contact line then leaves behind a hydrophobic layer in the oil, while on the water side the hydrophilic substrate remains bare (see also Figure 1A). Divalent cations and a sufficiently high $\mathrm{pH}$ in the brine are required for this effect to take place: the formation of the organometallic complexes requires deprotonation of the fatty acids, while the divalent cations that replace the protons also facilitate the subsequent binding to mica or silica substrates. Higher concentrations of the cations lead to a further increase of the contact angle. ${ }^{8}$

The effects of temperature and bicarbonate ions on the contact angle were examined using mica substrates and oil with $0.1 \mathrm{mM}$ C16. To avoid any possible $\mathrm{pH}$ effects, all solutions (with and without added bicarbonate) were adjusted to $\mathrm{pH} 8$, at room temperature (RT), shortly before the measurement. Results are shown in Figure 2A. For the droplets without
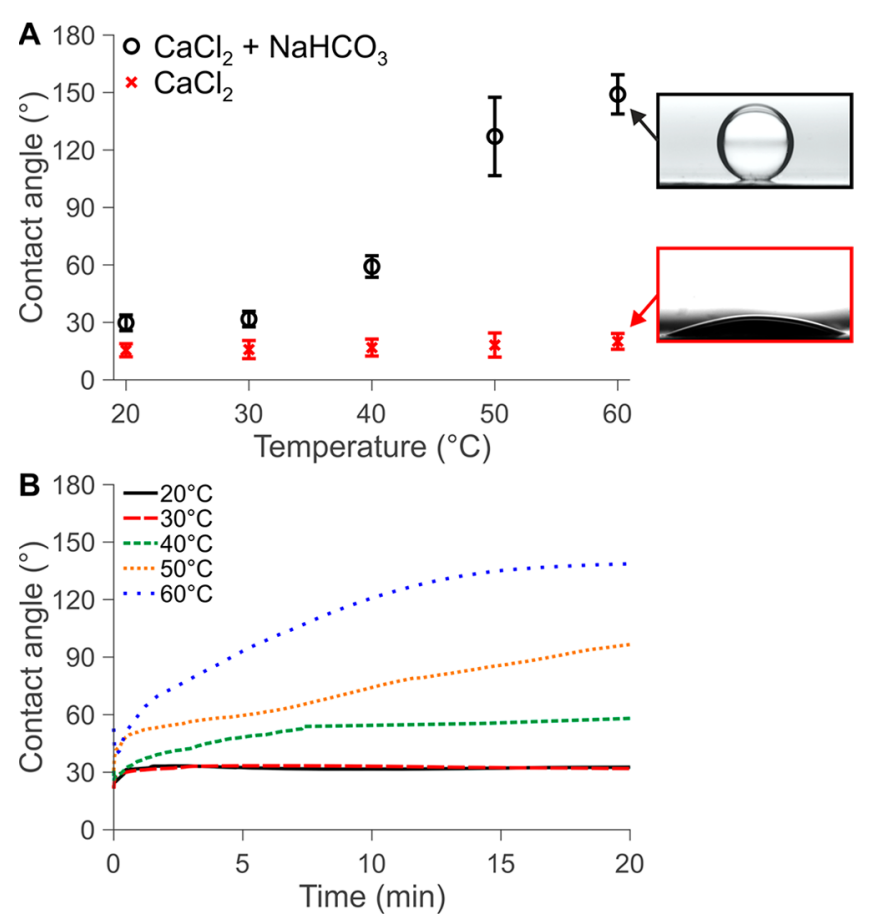

Figure 2. Temperature effect on wettability (i.e., water contact angle) of brine droplets on mica, immersed in decane with $0.1 \mathrm{mM} \mathrm{C16.} \mathrm{(A)}$ Final contact angles and standard deviations for droplets with/without $2 \mathrm{mM} \mathrm{NaHCO}_{3}$ along with example pictures. (B) Time dependence of the contact angle for the droplets with the $\mathrm{NaHCO}_{3}$. Brine composition: $10 \mathrm{mM} \mathrm{CaCl}$ (and $2 \mathrm{mM} \mathrm{NaHCO}_{3}$ when specified), $\mathrm{pH} 8$. 
added bicarbonate, the autophobing effect is weak, resulting in water contact angles of about $20^{\circ}$. This is likely due to the low concentration of $\mathrm{CaCl}_{2}(10 \mathrm{mM})$ used in comparison to earlier work. ${ }^{8}$ Without bicarbonate we also do not perceive any significant effect of temperature on the wetting properties. In contrast, in the presence of $2 \mathrm{mM} \mathrm{NaHCO}$ in the brine, contact angles are markedly increased and continue to rise with increasing temperature: up to $150^{\circ}$ at $60^{\circ} \mathrm{C}$.

We also observe a change in the autophobing kinetics in the presence of added bicarbonate: whereas it takes about $1 \mathrm{~min}$ for droplets below $40{ }^{\circ} \mathrm{C}$ to reach a stable conformation, at higher temperatures that time increases to about $20 \mathrm{~min}$ (Figure 2B). The diameter of the droplets is $\sim 2 \mathrm{~mm}$ at maximal spreading; therefore, the contact line moves with an average speed of $\sim 0.1 \mathrm{~mm} / \mathrm{min}$ (it starts out faster and slows down over time). We observed that when $1 \mathrm{mM} \mathrm{C} 16$ is present in the oil (instead of $0.1 \mathrm{mM}$ ), the final contact angle remains the same but the contact line speed is increased $\sim 10$ times.

We also investigated the effects of the initial $\mathrm{pH}$ of the brine phase. The high contact angle found at $60{ }^{\circ} \mathrm{C}$ appears to persist as the droplet $\mathrm{pH}$ gets lowered to 6.5 (Figure 3A): it

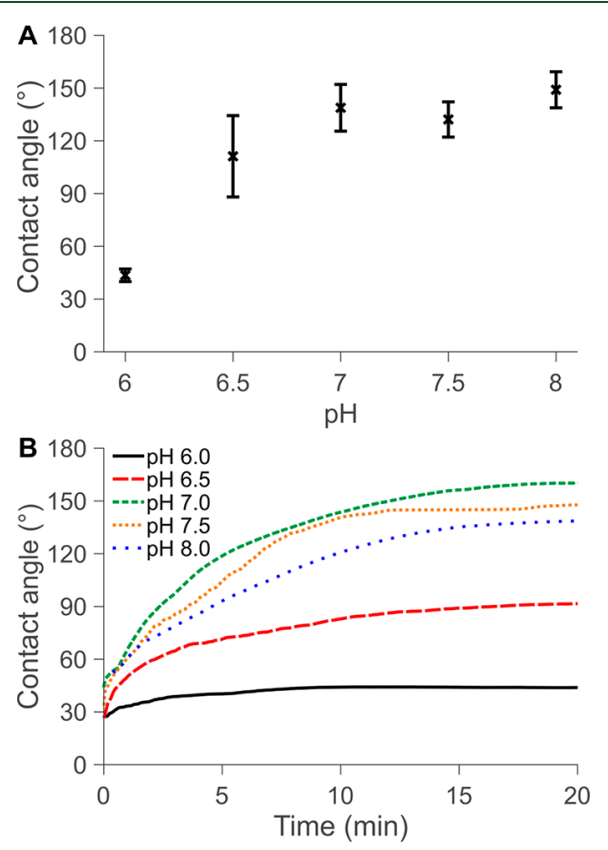

Figure 3. Effect of $\mathrm{pH}$ (set at RT) on the wettability. (A) Final contact angles and standard deviations. (B) Time-dependent contact angles. Conditions: mica substrate, $0.1 \mathrm{mM} \mathrm{C} 16$ in decane, $10 \mathrm{mM}$ $\mathrm{CaCl}_{2}$ and $2 \mathrm{mM} \mathrm{NaHCO}_{3}$ in the brine, $60{ }^{\circ} \mathrm{C}$. Note that $\mathrm{B}$ shows examples of measurements on individual drops; final contact angles do therefore not necessarily match the averaged values shown in A.

still reaches a value of about $120^{\circ}$. At $\mathrm{pH} 6$ the droplets only reach contact angles of about $40^{\circ}$, but a slow autophobing still occurs (Figure 3B), meaning that there is still some effect of the bicarbonate present.

At reservoir conditions a large variety of amphiphilic molecules, including weak acids, is present in the oil. ${ }^{4}$ This makes it relevant to examine how the molecular architecture of the carboxylic acid affects the high-temperature bicarbonate effect. Figure 4 shows the final contact angles obtained for 13 carboxylic acids. Eight of them have linear aliphatic tail groups with a different (even) number of carbon atoms (C6-C20). For these fatty acids the final contact angle shows a monotonic

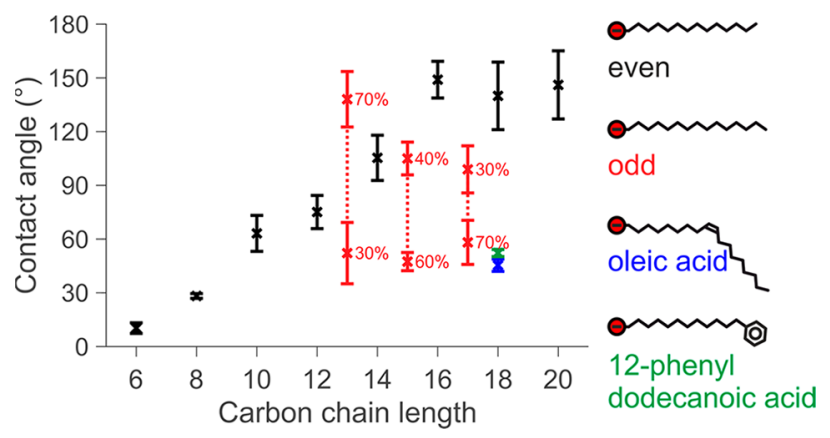

Figure 4. Effect of the molecular architecture of the carboxylic acid on the wettability: final water contact angles along with their standard deviations. Odd carbon chain length data has been split up in two populations (approximate percentage of data points is shown): slow, strong autophobing (high contact angle) and faster, weak autophobing (low contact angle). Conditions: mica substrate, 0.1 $\mathrm{mM}$ carboxylic acid in decane, $10 \mathrm{mM} \mathrm{CaCl}_{2}$ and $2 \mathrm{mM} \mathrm{NaHCO}_{3}$ in brine at $\mathrm{pH} 8,60^{\circ} \mathrm{C}$.

increase with chain length. At the shortest chain length of 6 carbon atoms we do not observe the strong, slow autophobing behavior described above. For C10 the autophobing effect starts to become apparent, and for $\mathrm{C} 16$ it levels off to a contact angle plateau of around $150^{\circ}$. For odd chain lengths we find a different behavior with a large spread of final contact angles. Only a fraction of the droplets showed a strong (and slow) autophobing behavior, while others showed a weak (and quick) autophobing. This indicates a large contact angle hysteresis, which could be associated with a chemically inhomogeneous substrate. Two carboxylic acids with a more complex architecture, oleic- and 12-phenyl dodecanoic acid, still show the slow autophobing effect but with a diminished final contact angle of around $50^{\circ}$.

The found relation between tail-group architecture and wetting phenomenology indicates that the self-assembly of the different carboxylic acids on the mica leads to significant differences in the structure of the hydrophobic layer. We investigated these structures in more detail by ex situ AFM imaging in air. A drawback of studying substrates obtained after autophobing is that there was no control over the velocity of the contact line. Variations in this velocity were earlier found to cause an inhomogeneous deposition of material. ${ }^{29} \mathrm{We}$ observed this also in our samples: substrate coverage increased when approaching the final contact line from the outside of the droplet (compare Figure 5B and 5C, left column). Anticipating a better insight into the layer formation process from experiments where this velocity is better controlled, we did experiments where the mica was dip coated through the oil/ brine interface. We chose velocities of 0.1 or $1 \mathrm{~mm} / \mathrm{min}$, reflecting the average contact line speed of autophobing droplets at 0.1 and $1 \mathrm{mM} \mathrm{C16,} \mathrm{respectively.} \mathrm{To} \mathrm{examine} \mathrm{the}$ layer homogeneity and to ensure representative images we scanned three or more areas several millimeters apart and in some cases also on different samples prepared at identical conditions. We found that dip coating indeed resulted in a more homogeneous distribution of organic layers across and between samples.

To illustrate the differences and similarities between the coating methods, we compare samples obtained under otherwise identical chemical conditions: $\mathrm{pH} 8,10 \mathrm{mM} \mathrm{CaCl}_{2}$ in the brine, and $1 \mathrm{mM} \mathrm{C} 16$ in the oil. Two cases are considered: one in the absence (Figure 5A) and one in the 

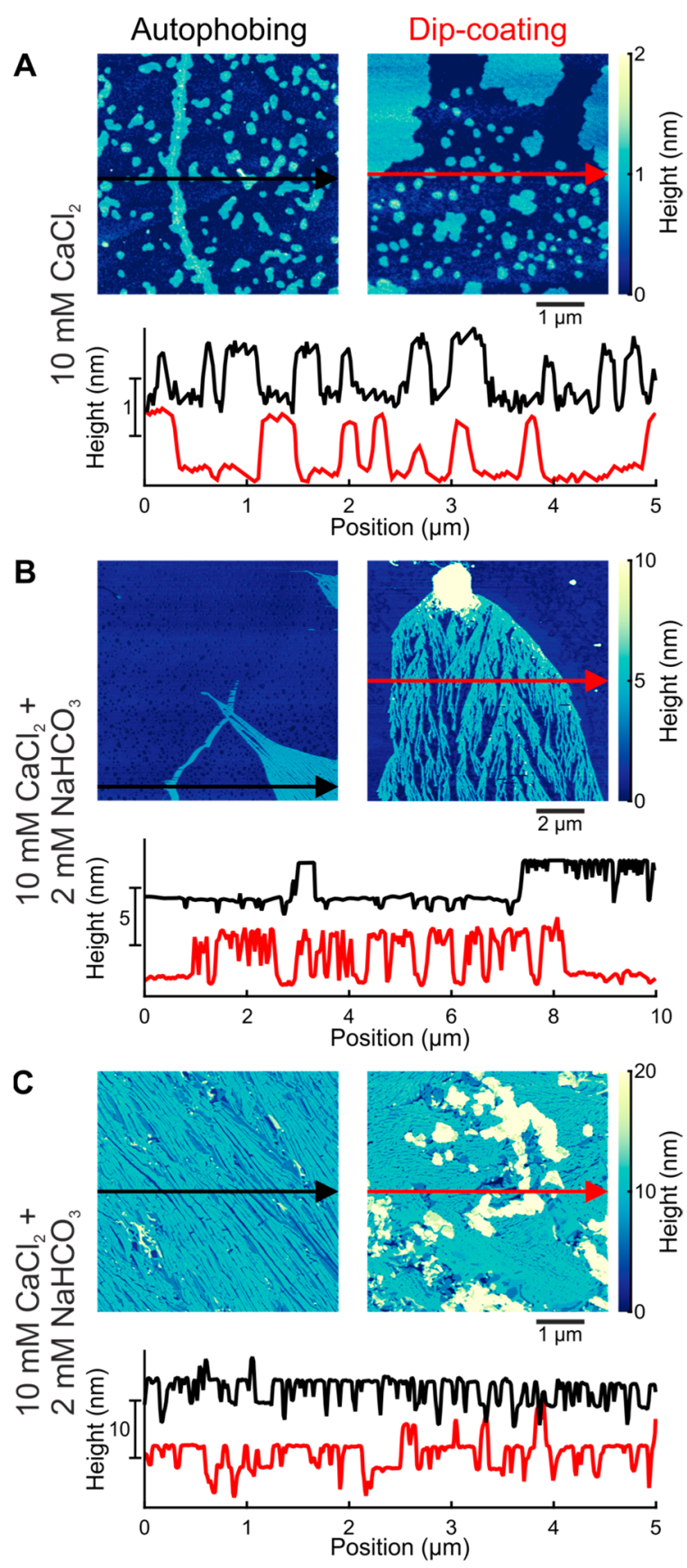

Figure 5. AFM height images and cross sections of organic layers formed on mica by autophobing (left, black) and dip coating (right, red): (A) without $\mathrm{NaHCO}_{3}$, (B) with $2 \mathrm{mM} \mathrm{NaHCO}_{3}$ at a mono- to multilayer transition region, (C) with $2 \mathrm{mM} \mathrm{NaHCO}_{3}$ at a multilayer region. Note the height scale variation across subfigures. Line profiles in the black have been shifted for clarity. Preparation conditions: 60 ${ }^{\circ} \mathrm{C}$, mica substrate, decane containing $1 \mathrm{mM} \mathrm{C} 16$, brine containing 10 $\mathrm{mM} \mathrm{CaCl} 2, \mathrm{pH} 8$, dipping speed $1 \mathrm{~mm} / \mathrm{min}$.

presence of an additional $2 \mathrm{mM}$ of $\mathrm{NaHCO}_{3}$ in the brine (Figure 5B and 5C). Without the added bicarbonate, both autophobing and dip-coating experiments produce island-like structures with a distribution of lateral length scales ranging from $\sim 0.1$ to $\sim 1 \mu \mathrm{m}$. While there are some differences in lateral morphology, all islands have a height of around $1 \mathrm{~nm}$ (Figure 5A), corresponding to a monolayer of C16 (see eq 1). It should be noted that the morphology of these islands is variable across the substrate, especially in the case of the autophobing droplet, but the thickness is always constant. In the presence of $2 \mathrm{mM} \mathrm{NaHCO}_{3}$ the structures look very different: both experiments now produce a much higher coverage, and also the layer thickness is much higher from $\sim 5$ (Figure 5B) to $\sim 20 \mathrm{~nm}$ (Figure 5C). The layers appear to consist of units about $5 \mathrm{~nm}$, apparent from the cross sections. Also, the lateral geometry changes (for both methods) from disordered islands to a more lamellar structure with occasional branching (see also Supplementary Figure S2). It thus appears that the effect of bicarbonate gets most strongly reflected in the coverage and layer thickness, while the dipping experiments can reproduce the trends as found with the autophobing droplets.

We therefore continue our investigation with dip-coating experiments. Decreasing the pulling speed from 1.0 to $0.1 \mathrm{~mm} /$ min makes the layered-plateau structure more apparent (Figure 6 , in comparison to Figure 5). Increasing the concentration of C16 present during dip coating also makes the plateaus more pronounced: a comparison of samples prepared at $0.1,1$, and $10 \mathrm{mM}$ (Figure $6 \mathrm{~A}-\mathrm{C}$ and $6 \mathrm{D}-\mathrm{F}$ ) shows increasing lateral extensions and better visible steps of the aforementioned $5 \mathrm{~nm}$ discrete layers; this is most noticeable in Figure 6F. It is remarked here that while AFM imaging was typically performed near the upper edge of the deposited layers (formed most quickly after the start of the experiment), also the lower edges were inspected. These layers, which were formed $2-3 \mathrm{~h}$ later $(0.1 \mathrm{~mm} / \mathrm{min}$ pulling speed, $1-2 \mathrm{~cm}$ long slides), showed no structural differences in the layering. This suggests the absence of aging effects.

To further study the discrete layering we performed additional analysis on samples prepared under the same conditions as for Figure 6C. Using AFM imaging at higher lateral resolution $(1024 \times 1024$ instead of $512 \times 512$ pixels, 20 $\times 20 \mu \mathrm{m})$ we get a detailed picture with many discrete layer steps (Figure 7A). An image of the same sample with SEM (Figure 7B) shows that the layers are mostly flat, with occasionally some larger structures of stacked platelets. The lack of contrast in the lower layers suggests that the entire surface is covered with an organic layer, meaning that what we indicate as "zero" height in the AFM image is likely not the mica but rather the lowest organic layer.

By transforming the AFM height map into a histogram, the layering can be studied in more detail (Figure 7A). Taking the peak-to-peak distances of the histograms of this image as well as the $2 \times 2 \mu \mathrm{m}$ image of this sample (see Supplementary Figure S3F) we find a mean layer thickness of $4.6 \mathrm{~nm}$ with a standard deviation of $0.30 \mathrm{~nm}$. The same sample was also analyzed by confocal Raman spectroscopy, where we found, besides mica and palmitic acid, evidence for the presence of carbonate due to a weak peak at $\sim 1080 \mathrm{~cm}^{-1}$, corresponding to the symmetric stretching of carbonate (see Supplementary Figure S4). ${ }^{30}$ A sample exposed to an autophobing droplet at the same conditions was also analyzed by XPS, showing the presence of both $\mathrm{Ca}$ and $\mathrm{C}=\mathrm{O}$ (see Supplementary Figure S5), but the latter can be either from carbonate species or from the carboxylate group of the fatty acids.

A similar analysis was performed using different linear fatty acids: C8, C12, and C20 (see Supplementary Figure S3). C6 was excluded from this analysis since here the autophobing effect was weak and the amount of deposited hydrophobic material was small. This might be related to the fact that this short-chain fatty acid can dissolve both in water and in oil. Recording and combining multiple AFM images on the same 


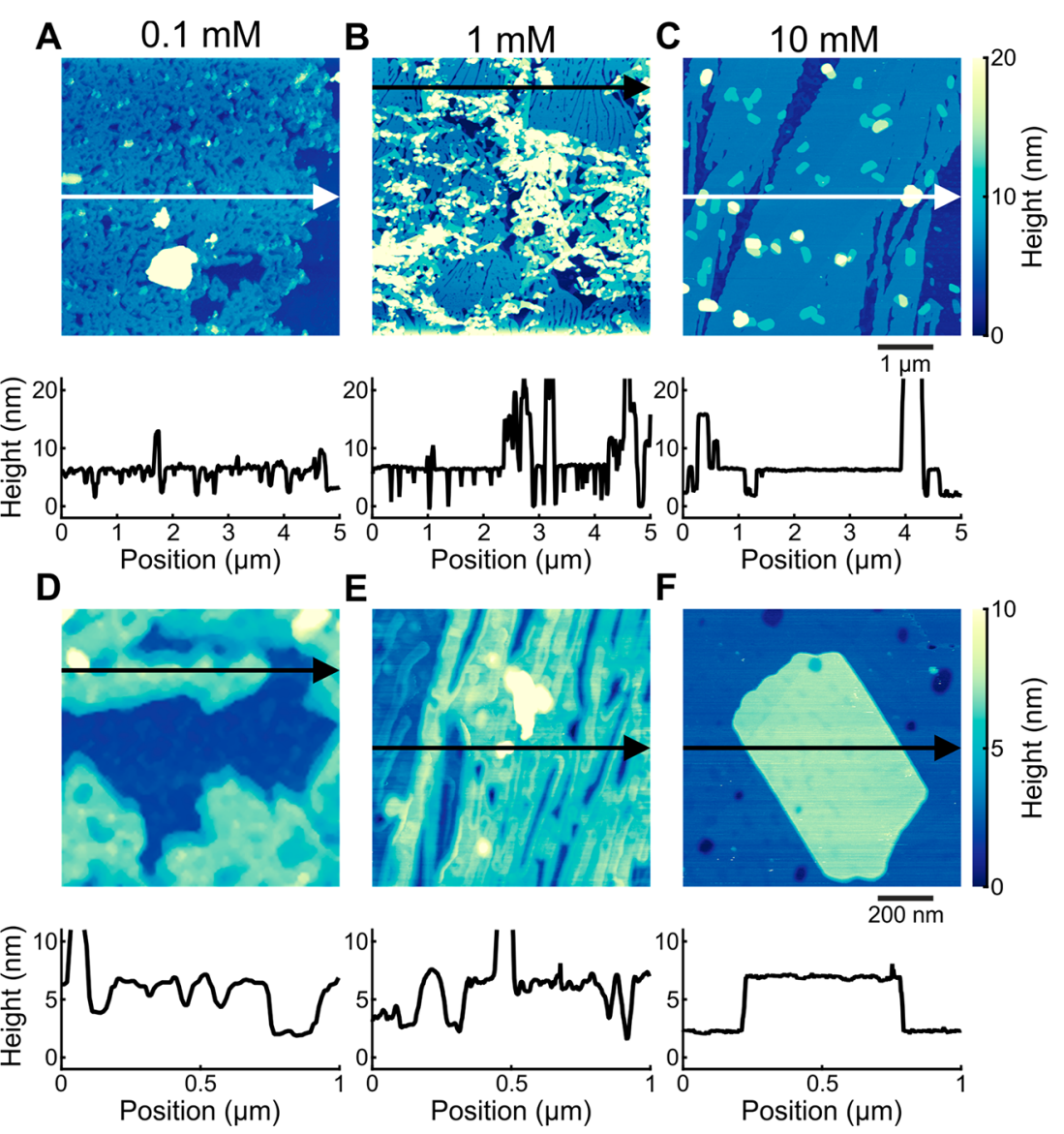

Figure 6. AFM height images and line profiles of organic layers formed on mica by dip coating. Preparation conditions: varying [C16], 10 $\mathrm{mM}$ $\mathrm{CaCl}_{2}, 2 \mathrm{mM} \mathrm{NaHCO}_{3}, \mathrm{pH} 8,60^{\circ} \mathrm{C}$, dipping speed $0.1 \mathrm{~mm} / \mathrm{min}$.
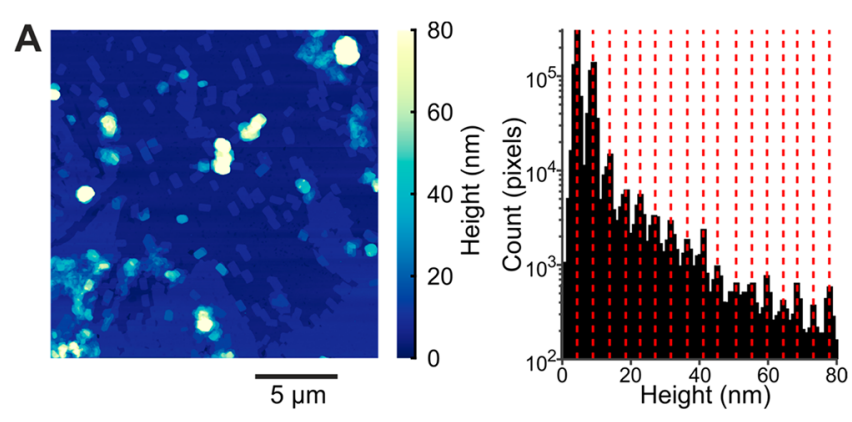

B

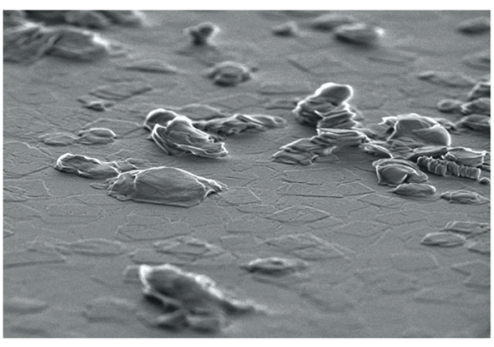

$1 \mu \mathrm{m}$

Figure 7. (A) AFM height image with corresponding histogram. (B) SEM image of organic layers formed on mica by dip coating. Red dashed lines illustrate the periodicity of the histogram. Preparation conditions: $10 \mathrm{mM} \mathrm{C16,10 \textrm {mM } \mathrm { CaCl }}, 2 \mathrm{mM} \mathrm{NaHCO}_{3}, \mathrm{pH} 8,60$ ${ }^{\circ} \mathrm{C}$, dipping speed $0.1 \mathrm{~mm} / \mathrm{min}$.

samples, at locations several millimeters apart, allowed us to conclude that the overall coverage of multilayers increased with increasing chain length: a rare occurrence with C8, more prominence with $\mathrm{C} 12$, and almost full coverage with $\mathrm{C} 16$ and C20. These inspections (not shown) also revealed that the inhomogeneities occurred on a length scale of $O(1 \mathrm{~mm})$, which is too large to address with AFM. As a consequence, the AFM analysis of the samples prepared with $\mathrm{C} 8$ and $\mathrm{C} 12$ involved a scrutiny of the images for regions with thick multilayer areas. AFM images presented in Figure S3 are hence not representative in all respects. Focusing on the histograms for the layer height it turned out that all fatty acids (C8, C12, $\mathrm{C} 16$, and C20) show the same type of layering, where the thickness of the unit layer increases with chain length. On plotting the mean histogram peak-to-peak distances versus the carbon chain length, we find a linear relation with an extrapolated intercept ("no fatty acid") of $0.82 \mathrm{~nm}$ and a slope of $0.23 \mathrm{~nm}$ per carbon atom (Figure 8).

The results presented up to this point describe the formation of organic (multi)layers. Since they are deposited on the oil side of the contact line, it is plausible that the hydrophobic tails are sticking out. This is also corroborated by the increase in water contact angle after layer deposition (Figures 2 and 3). However, what matters for LSWF is not the formation but rather the removal of the hydrophobic organic layers. To examine this reverse process we flushed a brine droplet, deposited on mica in $n$-decane with $1 \mathrm{mM} \mathrm{C16}$ at $60{ }^{\circ} \mathrm{C}$, with deionized water. Within a few minutes this caused the droplet to spread again, indicating that the hydrophobic layer either desorbs or dissolves (Figure 9A). The same behavior was 


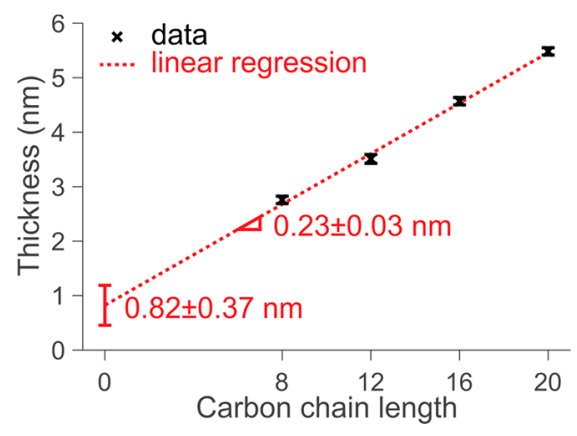

Figure 8. Thickness of the unit layer as a function of the carbon chain length for fatty acids deposited on mica slides by dip coating at $60{ }^{\circ} \mathrm{C}$. Thicknesses were obtained from AFM height histograms like Figures 7A and S3. Uncertainty ranges correspond to standard errors. Red dashed line is the result of linear regression. Other conditions: decane with $10 \mathrm{mM}$ fatty acid, brine with $10 \mathrm{mM} \mathrm{CaCl}_{2}, 2 \mathrm{mM} \mathrm{NaHCO}_{3}, \mathrm{pH}$ 8 , dipping speed $0.1 \mathrm{~mm} / \mathrm{min}$.

found for brine droplets on a silica substrate (see Supplementary Figure S6, and videos).

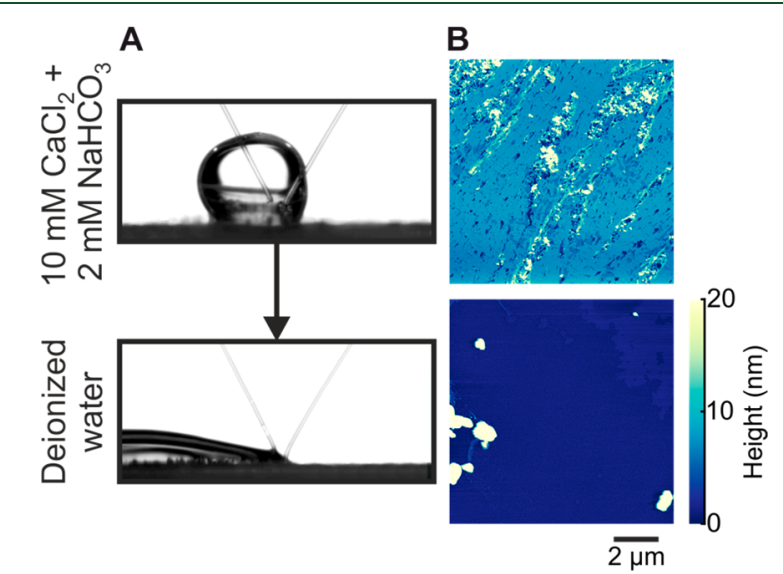

Figure 9. (A) Pictures of brine droplets on mica immersed in C16laden decane at $60{ }^{\circ} \mathrm{C}$ before (top) and after (bottom) replacing the droplet phase $\left(10 \mathrm{mM} \mathrm{CaCl}_{2}\right.$ and $\left.2 \mathrm{mM} \mathrm{NaHCO}_{3}\right)$ by deionized water. (B) AFM images showing that the distribution of organic material on the mica changes.

To confirm that the hydrophobic layer had indeed disappeared, we also submerged a mica slide which had been dip coated at $1 \mathrm{~mm} / \mathrm{min}$ (under otherwise the same conditions as in the droplet experiment) in deionized water at $60{ }^{\circ} \mathrm{C}$ for $30 \mathrm{~min}$. Comparing AFM images from before and after the brine replacement (Figure 9B), we found that the multilayers were mostly gone, leaving only a sparse coverage of monolayers and some larger aggregates.

\section{DISCUSSION}

Even though our experimental system is very simple compared to reservoir conditions, it is still host to complex phenomena. Unexpectedly, we observed a vastly different wetting behavior after a slight increase in temperature. This behavior was found for various carboxylic acids and could be attributed to synergistic effects of the presence of bicarbonate and elevated temperature. Given the complexity of real oil/brine/rock systems it cannot be excluded that other yet unidentified mechanisms play a role as well in real LSWF. Nonetheless, our current results are useful in gaining further insights in this EOR process.

From the macroscopic wettability experiments we found that low concentrations of bicarbonate ions have a strong effect on the wetting behavior in oil/brine/mineral systems at elevated temperatures up to $60{ }^{\circ} \mathrm{C}$, where they cause the final contact angle (CA) to increase to $\sim 150^{\circ}$, likely the result of higher coverage of dense organic layers. The effect requires the presence of calcium ions and carboxylic acids with chain lengths $\geq 8$ and temperatures $\geq 40{ }^{\circ} \mathrm{C}$. The CA increase gets stronger with higher temperature (Figure 2), $\mathrm{pH}$ (leveling off at $\geq 7$, Figure $3 \mathrm{~A}$ ), and carbon number of the fatty acid (plateauing at $\geq 16$, Figure 4). All of these trends are consistent with the explanation that $\mathrm{Ca}^{2+}$ and carbonate or bicarbonate ions get incorporated in the hydrophobic layers that are responsible for the CA increase. Raman spectroscopy data also indicate that some carbonate species are likely present in these layers (see Supplementary Figure S4).

The importance of elevated temperature for bicarbonate to have an effect on wettability is not immediately obvious from bulk speciation. Although $\mathrm{CaCO}_{3}$ precipitation is known to increase with temperature, our speciation calculations show that a significant fraction of the carbonate species should already precipitate at $20^{\circ} \mathrm{C}, \mathrm{pH} 8$ (Supplementary Figure S8), where we find no strong wettability effects of the bicarbonate. Also, in control experiments at $60^{\circ} \mathrm{C}, \mathrm{pH} \mathrm{8}$, aimed at revealing any solid formation in the aqueous phase, no such precipitation was observed (Supplementary Figure S9). The MINTEQ calculations show no significant temperature dependence on the fraction of $\mathrm{CaHCO}_{3}{ }^{+}$. We also find that no bulk precipitation of $\mathrm{CaCO}_{3}$ is to be expected at $60{ }^{\circ} \mathrm{C}, \mathrm{pH} 6-7$ (Supplementary Figure S7), whereas we do find a moderate to strong wettability effect under those conditions. This could still be consistent with $\mathrm{CaCO}_{3}$ formation taking place at the carboxylate groups at the oil-water interface. Whereas fatty acids in bulk are known to inhibit growth of $\mathrm{CaCO}_{3}$ through complexation, ${ }^{31,32}$ if they are present as ordered monolayers, e.g., at the oil-water interface, the same $\mathrm{Ca}^{2+}-$ carboxylate interaction enhances $\mathrm{CaCO}_{3}$ growth. ${ }^{21}$

The observed $\mathrm{pH}$ dependence of the wetting behavior likely stems from the deprotonation of carboxylate groups, a requirement for their surface activity and cation complexation. Even though the effective $\mathrm{p} K_{\mathrm{a}}$ of the $\mathrm{C} 16$ headgroup at the interface has been measured to be approximately $9,^{33}$ it is also known that certain cations can significantly lower the effective $\mathrm{p} K_{\mathrm{a}}$ of carboxylic acids in monolayers by inducing deprotonation. ${ }^{34-36}$ Previous wetting studies in similar systems at room temperature have also shown a similar transition occurring around $\mathrm{pH} 6{ }^{8}$ The calcium ions thus appear to play a double role: both deprotonation of the carboxylic acids and binding to carbonate or bicarbonate ions.

The increase of the contact angle with chain length (for even numbers, $\mathrm{C} 6-\mathrm{C} 20$ ) could be explained by an increase in the lateral packing density under the plausible assumption that predominantly the hydrophobic carbon chains will get exposed to the liquid phase. This denser packing would be driven by the well-known increased lateral interactions between the aliphatic chains. ${ }^{37}$ This point is corroborated by the odd-even effects (i.e., the deviating results for $\mathrm{C} 13, \mathrm{C} 15$, and $\mathrm{C} 17$ ) we observe, since odd and even fatty acids are known to orient in different lateral geometries, depending on the substrate, which can in turn affect macroscopic wettability or crystal growth. ${ }^{38,39}$ The diminished wettability found with bent 
(oleic acid) or laterally more bulky (phenyl dodecanoic acid) tail groups, which are known to exhibit weaker intermolecular hydrophobic interactions, ${ }^{24}$ also demonstrates the importance of a laterally dense and organized fatty acid layer.

The AFM images clearly demonstrated that the presence of bicarbonate ions induces thicker layers with higher coverage (Figure 5). The higher coverage could explain the higher contact angles in a simplistic rationalization using Cassie's law. ${ }^{40}$ As will be argued below, it is quite conceivable that the presence of carbonate or bicarbonate ions has a positive influence on the stability of densely packed calcium-fatty acid complexes, thus causing the high coverage.

Dip-coating experiments offered a way to study the architecture of the formed multilayers in more detail. The lateral structures obtained via dip coating are somewhat different from those formed via autophobing, but the unit layer thickness seems to be identical (Figure 5). Slower contact line motion or higher fatty acid concentration generates on average thicker multilayers with a higher coverage (Figure 6), but again the unit layer thickness remains the same (Figures 7C and S3). This suggests that the formation of the individual layers is governed by an equilibrium organizing principle that depends on chemical composition, but the number of layers that are formed does depend on kinetics.

An interesting aspect is that with multilayers not all layers can reside at an interface. The point that additional layers are formed in the oil thus implies a thermodynamic driving force for taking ions from the brine, binding them to fatty acids, and forming an insoluble layer in the oil. Also, the observation that the multilayer gets removed upon dilution of the brine suggests that a certain dissociation equilibrium (involving species in different fluid phases) is involved in the formation/ disintegration of the multilayers. In this picture, the fact that the multilayers tend to keep growing implies that substantial depletion of the species involved in the equilibrium (fatty acid, $\mathrm{Ca}^{2+}$, and possibly also $\mathrm{HCO}_{3}^{-}$) does not occur. Considering the amounts of mentioned species, the volume and area of the droplet, and the typical number of bilayers, a rough calculation indeed indicates that depletion should be insignificant.

The linear dependence of the unit thickness on the (even) carbon number for fatty acids (Figure 8 ) is striking. It supports the picture that those layers are highly organized, with the hydrocarbon tails collectively sticking out in the same direction. Increases in the carbon number of the tail group will then result in a proportional increase of the unit layer thickness. In images where the organics do not completely cover the mica, such as Figure 5B, the first layer seems slightly thicker than the subsequent ones (about 5-6 and $4 \mathrm{~nm}$, respectively), suggesting a difference in structure. The $1-2 \mathrm{~nm}$ extra in the lowest layer likely represents a template on top of which the additional layers grow. This is unlikely to be a film of $\mathrm{CaCO}_{3}$ grown directly on the mica, as the epitaxy for this configuration is known to be poor and therefore energetically unfavorable. ${ }^{41}$ More likely this is the same $\mathrm{Ca}^{2+}$-complexed fatty acid monolayer that forms without added bicarbonate.

Combining the foregoing observations and interpretations, we speculate that the multilayer structure starts with a monolayer of fatty acid bound to the mica via $\mathrm{Ca}^{2+}$, which is followed by multiple units of alternating fatty acid bilayers, where the bilayers are internally held together by $\mathrm{Ca}^{2+}$ cations and carbonate or bicarbonate anions, such as $\mathrm{CaCO}_{3}$ as shown in Figure $10 \mathrm{~A} . \mathrm{CaCO}_{3}$ is known to stabilize fatty acid bilayers in this manner, ${ }^{23}$ and divalent cations are known to bind fatty
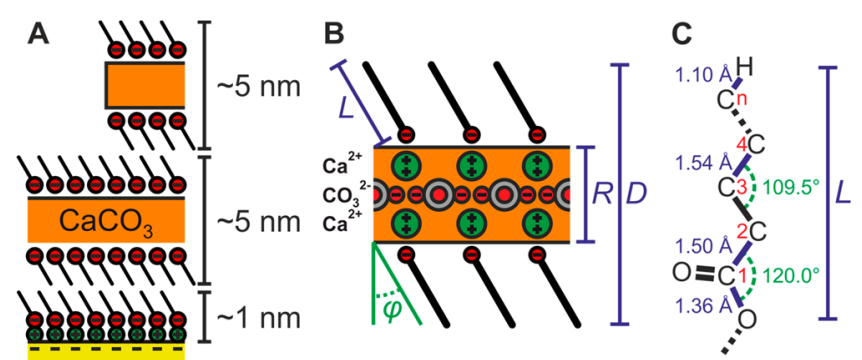

Figure 10. Speculative multilayer structure (A), geometry of a single discrete layer (B), and geometry of a single fatty acid molecule (C).

acid monolayers on calcite. ${ }^{19}$ The underlying monolayer is likely formed at the oil/water interface through adsorption and then deposited at the mica/oil interface. The subsequent multilayers must also be formed near the moving contact line, since the building blocks originate from different liquid phases. Our observation that the layer thickness depends on contact line speed is in agreement with this picture.

We can gain further insight into the proposed intermediate $\mathrm{Ca}^{2+}$ and carbonate species layer by revisiting the linear relation $D(n)$ between unit layer thickness and aliphatic chain length (Figure 8). Even though the obtained intercept and slope have significant standard errors, being $0.82 \pm 0.37$ and $0.23 \pm 0.03 \mathrm{~nm}$, they can be used to estimate the thickness $R$ of the intermediate layer under certain assumptions. We assume the geometry proposed in Figure 10, with unit layer thickness $D$, and fatty acids as rigid rods of length $L$ under a tilt angle $\varphi$. These assumptions can be justified because densely packed layers are known to be composed of straightened tail groups, ${ }^{42}$ which can be tilted depending on temperature and packing density. ${ }^{43}$ We can calculate $L$ as the distance from the furthest oxygen atom in the headgroup to the furthest hydrogen atom in the tail group (Figure 10C) as a function of the carbon number $n$. All of the bond lengths and angles involved are known, ${ }^{44}$ so this can be worked out geometrically (in nanometers)

$$
L(n)=0.08+0.13 n \text { for } n \geq 2
$$

The solution is only valid for $n \geq 2$, because formic acid ( $n=$ 1) has no $\mathrm{sp}^{3}$-hybridized carbon and therefore lacks some of the specific bond lengths and angles used in this calculation. Using this equation and accounting for a universal tilt and the van der Waals radius of the terminal hydrogen, ${ }^{45}$ we find the linear relation $D(n)$ with an intercept at $R+0.24+0.16 \times \cos$ $\varphi \mathrm{nm}$ and a slope of $0.26 \times \cos \varphi \mathrm{nm}$. Using the known values from Figure 10 we find $\varphi \approx 28^{\circ}$ and $R \approx 0.5 \mathrm{~nm}$. This remarkably small thickness suggests that the organizing effect of carbonate species on the layer structure is achieved by very few carbonate groups, too few to justify direct comparison with properties of bulk $\mathrm{CaCO}_{3}$ phases, as it is slightly smaller than the size of a unit cell (for calcite or aragonite). Considering the uncertainty in $R$, an arrangement of planes of calcium and carbonate ions, as sketched in Figure 10B, might still be possible. In this context is noteworthy that $\mathrm{CaCO}_{3}$ is known to organize in this way when grown simultaneously with fatty acid monolayers, from molecular dynamics studies ${ }^{46,47}$ and X-ray diffraction experiments. ${ }^{21,22}$

The value of $\varphi$ can be used to infer the lateral headgroup spacing, which could correspond to the spacing between $\mathrm{Ca}^{2+}$ ions in the plane underneath (c.f. Figure 10A). In dense fatty acid monolayers, tail groups tend to pack in hexagonal 
geometries due to their lateral affinity. The typical distance is then around $0.47 \mathrm{~nm} .{ }^{42}$ If the headgroup spacing is larger than this, for instance, if the fatty acids are grafted to a template, the tail groups can tilt toward each other to maintain the tail-group spacing (Figure 10B). The shortest distance between $\mathrm{Ca}^{2+}$ ions in crystalline $\mathrm{CaCO}_{3}$ is typically around $0.50 \mathrm{~nm}$. In the case of $\mathrm{CaCO}_{3}$ growth in the presence of a fatty acid monolayer, the latter is known to act as a flexible template for $\mathrm{CaCO}_{3}$ nucleation. ${ }^{46,48}$ This flexibility could accommodate for the discrepancy between the mentioned spacing. Our inference of a tilt of around $28^{\circ}$ supports a scenario where the headgroup spacing is increased during the formation of a fatty acid$\mathrm{CaCO}_{3}$ interface.

Considering some of the conditions explored, an extrapolation of our findings to the scope of real enhanced oil recovery might be possible. Bicarbonate ions are present at millimolar concentrations in some reservoir brines ${ }^{49}$ and in seawater ${ }^{50}$ as used in secondary oil recovery. The explored $\mathrm{pH}$ range of 6-8 (Figure 3) corresponds to reservoir brine during water flooding. ${ }^{51}$ Any effects of carbonate species on lowsalinity water flooding in cores is typically ascribed to its effect on bulk $\mathrm{pH} .^{16,17}$ Our work demonstrates that surface complexation of carbonate species and surface active groups might also play an important role. From the temperature variation (Figure 2) we found that the wettability change due to bicarbonate occurs from $40{ }^{\circ} \mathrm{C}$ onward, at least up to $60{ }^{\circ} \mathrm{C}$, which corresponds to temperatures of low-to-intermediate depth reservoirs. ${ }^{15}$ Also, the mineral substrates of our experiments, mica and silica, are similar to that of sandstone reservoirs: aluminosilicates and quartz.

However, some significant differences remain between the organic phase in our model system and real crude oil. Other than simple carboxylic acids, crude oils contain a large variety of naphthenic acids, aromatic acids, and asphaltenes that are known to play significant roles in surface adsorption and wettability. ${ }^{52}$ On the other hand, carboxylic acids, and particularly fatty acids, are known to be disproportionally produced from sandstone core floods with low-salinity water, as compared to the other organic compounds. ${ }^{4}$ This suggests that the reversible adsorption and precipitation of fatty acids does likely play a key role in the salinity-dependent wetting properties of the reservoir, as it does in our simplified model system. Hence, even experiments on simple model systems can be valuable in elucidating some specific mechanisms involved in LSWF.

\section{CONCLUSION}

A model system for enhanced oil recovery through LSWF, containing brine, oil with carboxylic acid, and mica surface, was used to study wettability alterations at elevated temperatures up to $60{ }^{\circ} \mathrm{C}$. Most experiments involved the deposition of hydrophobic organic layers, giving rise to increasing water contact angles. Above $40{ }^{\circ} \mathrm{C}$ a remarkable enhancement of this effect was found, provided that besides $\mathrm{Ca}^{2+}$ ions there were also bicarbonate ions in the brine (at $\mathrm{pH} 8$ ). This same effect was found for a variety of carboxylic acids and was the strongest for fatty acids with even carbon numbers $\geq 16$. The hydrophobic organic layers appear to consist of stacked bilayers of carboxylic acids,bound together by very thin layers that contain $\mathrm{Ca}^{2+}$ and presumably also carbonate species. This new insight into wettability alteration might help in understanding the complex salinity-dependent wetting behavior of sandstone reservoirs. In particular, since seawater contains around $2 \mathrm{mM}$ bicarbonate ions, allowing seawater to flood the sandstone reservoir could actually promote the formation of hydrophobic surface structures, especially if no carbonate species were present in the reservoir brine.

\section{ASSOCIATED CONTENT}

\section{S Supporting Information}

The Supporting Information is available free of charge on the ACS Publications website at DOI: 10.1021/acs.energyfuels.9b01351.

Schematic of the setup for measuring contact angles at elevated temperatures; composite of three AFM height images of hydrophobic layers formed on mica by dip coating; AFM height images and corresponding histograms of hydrophobic layers formed on mica by dip coating using varying fatty acids; Raman spectra of multilayers; XPS profiles for the occurrence of various elements in the trail left behind by the contactline; experiment where the contents of a droplet are replaced while maintaining droplet volume; MINTEQ calculations showing ion speciation inside the brine, depending on temperature and $\mathrm{pH}$; brine/oil aging experiment at $60{ }^{\circ} \mathrm{C}$ aimed at (dis) proving precipitation or $\mathrm{pH}$ changes (PDF)

\section{AUTHOR INFORMATION}

\section{Corresponding Author}

*E-mail: m.h.g.duits@utwente.nl.

ORCID 8

Martin E. J. Haagh: 0000-0002-6413-4708

Michel H. G. Duits: 0000-0003-1412-4955

Notes

The authors declare no competing financial interest.

\section{ACKNOWLEDGMENTS}

This work is part of the research program Rock-on-a-Chip with project number i40, which is cofinanced by The Netherlands Organization for Scientific Research (NWO) and by the Exploratory Research (ExploRe) program of BP plc. BP Exploration Operating Co. Ltd. are thanked for permission to publish this paper. We thank Sachin Nair for technical support with Raman spectrometry, Igor Siretanu for discussions, and Mark Smithers for technical support with SEM.

\section{REFERENCES}

(1) Muggeridge, A.; Cockin, A.; Webb, K.; Frampton, H.; Collins, I.; Moulds, T.; Salino, P. Recovery rates, enhanced oil recovery and technological limits. Philos. Trans. R. Soc., A 2014, 372 (2006), 20120320.

(2) McGuire, P. L.; Chatham, J. R.; Paskvan, F. K.; Sommer, D. M.; Carini, F. H. Low Salinity Oil Recovery: An Exciting New EOR Opportunity for Alaska's North Slope; Society of Petroleum Engineers, 2005.

(3) Webb, K. J.; Black, C. J. J.; Al-Ajeel, H. Low Salinity Oil Recovery - Log-Inject-Log. SPE/DOE Symposium on Improved Oil Recovery; Society of Petroleum Engineers: Tulsa, OK, 2004; p 7.

(4) Collins, I. R.; Couves, J. W.; Hodges, M.; McBride, E. K.; Pedersen, C. S.; Salino, P. A.; Webb, K. J.; Wicking, C.; Zeng, H. Effect of Low Salinity Waterflooding on the Chemistry of the Produced Crude Oil. SPE Improved Oil Recovery Conference; Society of Petroleum Engineers: Tulsa, OK, USA, 2018; p 17. 
(5) Jackson, M.; Vinogradov, J.; Hamon, G.; Chamerois, M. Evidence, mechanisms and improved understanding of controlled salinity waterflooding part 1: Sandstones. Fuel 2016, 185, 772-793.

(6) Myint, P. C.; Firoozabadi, A. Thin liquid films in improved oil recovery from low-salinity brine. Curr. Opin. Colloid Interface Sci. 2015, 20 (2), 105-114.

(7) Al-Shalabi, E. W.; Sepehrnoori, K. A comprehensive review of low salinity/engineered water injections and their applications in sandstone and carbonate rocks. J. Pet. Sci. Eng. 2016, 139, 137-161.

(8) Bera, B.; Duits, M. H. G.; Cohen Stuart, M. A.; van den Ende, D.; Mugele, F. Surfactant induced autophobing. Soft Matter 2016, 12 (20), 4562-4571.

(9) Haagh, M. E. J.; Siretanu, I.; Duits, M. H. G.; Mugele, F. SalinityDependent Contact Angle Alteration in Oil/Brine/Silicate Systems: the Critical Role of Divalent Cations. Langmuir 2017, 33 (14), 33493357.

(10) Cannan, R. K.; Kibrick, A. Complex formation between carboxylic acids and divalent metal cations. J. Am. Chem. Soc. 1938, 60 (10), 2314-2320.

(11) Kobayashi, K.; Liang, Y.; Murata, S.; Matsuoka, T.; Takahashi, S.; Amano, K.-i.; Nishi, N.; Sakka, T. Stability Evaluation of Cation Bridging on Muscovite Surface for Improved Description of IonSpecific Wettability Alteration. J. Phys. Chem. C 2017, 121 (17), 9273-9281.

(12) Wang, X.; Lee, S. Y.; Miller, K.; Welbourn, R.; Stocker, I.; Clarke, S.; Casford, M.; Gutfreund, P.; Skoda, M. W. A. Cation Bridging Studied by Specular Neutron Reflection. Langmuir 2013, 29 (18), 5520-5527.

(13) Mugele, F.; Bera, B.; Cavalli, A.; Siretanu, I.; Maestro, A.; Duits, M.; Cohen-Stuart, M.; van den Ende, D.; Stocker, I.; Collins, I. Ion adsorption-induced wetting transition in oil-water-mineral systems. Sci. Rep. 2015, 5, 10519.

(14) Haagh, M. E. J.; Schilderink, N.; Duits, M. H. G.; Siretanu, I.; Mugele, F.; Collins, I. R. Salinity-dependent contact angle alteration in oil/brine/silicate systems: The effect of temperature. J. Pet. Sci. Eng. 2018, 165, 1040-1048.

(15) Bjørlykke, K.; Jahren, J. Sandstones and Sandstone Reservoirs. In Petroleum Geoscience: From Sedimentary Environments to Rock Physics, Bjorlykke, K., Ed.; Springer Berlin Heidelberg: Berlin, Heidelberg, 2010; pp 113-140.

(16) RezaeiDoust, A.; Puntervold, T.; Austad, T. Chemical Verification of the EOR Mechanism by Using Low Saline/Smart Water in Sandstone. Energy Fuels 2011, 25 (5), 2151-2162.

(17) Pu, H.; Xie, X.; Yin, P.; Morrow, N. R. Low-Salinity Waterflooding and Mineral Dissolution. SPE Annual Technical Conference and Exhibition; Society of Petroleum Engineers: Florence, Italy, 2010; p 17.

(18) Brady, P. V.; Krumhansl, J. L.; Mariner, P. E. Surface Complexation Modeling for Improved Oil Recovery. SPE Improved Oil Recovery Symposium; Society of Petroleum Engineers: Tulsa, OK, USA, 2012; p 10.

(19) Rezaei Gomari, K. A.; Hamouda, A. A. Effect of fatty acids, water composition and $\mathrm{pH}$ on the wettability alteration of calcite surface. J. Pet. Sci. Eng. 2006, 50 (2), 140-150.

(20) Austad, T.; Standnes, D. C. Spontaneous imbibition of water into oil-wet carbonates. J. Pet. Sci. Eng. 2003, 39 (3), 363-376.

(21) Travaille, A. M.; Kaptijn, L.; Verwer, P.; Hulsken, B.; Elemans, J. A. A. W.; Nolte, R. J. M.; van Kempen, H. Highly Oriented SelfAssembled Monolayers as Templates for Epitaxial Calcite Growth. J. Am. Chem. Soc. 2003, 125 (38), 11571-11577.

(22) Han, Y.-J.; Aizenberg, J. Face-Selective Nucleation of Calcite on Self-Assembled Monolayers of Alkanethiols: Effect of the Parity of the Alkyl Chain. Angew. Chem., Int. Ed. 2003, 42 (31), 3668-3670.

(23) Damle, C.; Kumar, A.; Sainkar, S. R.; Bhagawat, M.; Sastry, M. Growth of Calcium Carbonate Crystals within Fatty Acid Bilayer Stacks. Langmuir 2002, 18 (16), 6075-6080.

(24) Brzozowska, A. M.; Mugele, F.; Duits, M. H. G. Stability and interactions in mixed monolayers of fatty acid derivatives on Artificial Sea Water. Colloids Surf., A 2013, 433, 200-211.
(25) Shiao, S. Y.; Chhabra, V.; Patist, A.; Free, M. L.; Huibers, P. D. T.; Gregory, A.; Patel, S.; Shah, D. O. Chain length compatibility effects in mixed surfactant systems for technological applications. Adv. Colloid Interface Sci. 1998, 74 (1), 1-29.

(26) Goebel, A.; Lunkenheimer, K. Interfacial tension of the water/ n-alkane interface. Langmuir 1997, 13 (2), 369-372.

(27) de Poel, W.; Pintea, S.; Drnec, J.; Carla, F.; Felici, R.; Mulder, P.; Elemans, J. A. A. W.; van Enckevort, W. J. P.; Rowan, A. E.; Vlieg, E. Muscovite mica: Flatter than a pancake. Surf. Sci. 2014, 619, 1924.

(28) Qu, D.; Suter, R.; Garoff, S. Surfactant Self-Assemblies Controlling Spontaneous Dewetting. Langmuir 2002, 18 (5), 16491654.

(29) Bera, B. Ion and surfactant induced wetting transition; Universiteit Twente, 2016.

(30) Buzgar, N.; Apopei, A. I. The Raman study of certain carbonates. Geologie. Tomul LV 2009, 2, 97-112.

(31) Westin, K. J.; Rasmuson, Å. C. Crystal growth of aragonite and calcite in presence of citric acid, DTPA, EDTA and pyromellitic acid. J. Colloid Interface Sci. 2005, 282 (2), 359-369.

(32) Wada, N.; Kanamura, K.; Umegaki, T. Effects of Carboxylic Acids on the Crystallization of Calcium Carbonate. J. Colloid Interface Sci. 2001, 233 (1), 65-72.

(33) Adams, E.; Allen, H. Palmitic Acid on Salt Subphases and in Mixed Monolayers of Cerebrosides: Application to Atmospheric Aerosol Chemistry. Atmosphere 2013, 4 (4), 315.

(34) Le Calvez, E.; Blaudez, D.; Buffeteau, T.; Desbat, B. Effect of Cations on the Dissociation of Arachidic Acid Monolayers on Water Studied by Polarization-Modulated Infrared Reflection-Absorption Spectroscopy. Langmuir 2001, 17 (3), 670-674.

(35) Kundu, S.; Langevin, D. Fatty acid monolayer dissociation and collapse: Effect of $\mathrm{pH}$ and cations. Colloids Surf., A 2008, 325 (1-2), $81-85$.

(36) Tang, C. Y.; Allen, H. C. Ionic Binding of Na+ versus K+ to the Carboxylic Acid Headgroup of Palmitic Acid Monolayers Studied by Vibrational Sum Frequency Generation Spectroscopy. J. Phys. Chem. A 2009, 113 (26), 7383-7393.

(37) Rakshit, A. K.; Zografi, G.; Jalal, I. M.; Gunstone, F. D. Monolayer properties of fatty acids: II. Surface vapor pressure and the free energy of compression. J. Colloid Interface Sci. 1981, 80 (2), 466473.

(38) Tao, F.; Bernasek, S. L. Understanding odd- even effects in organic self-assembled monolayers. Chem. Rev. 2007, 107 (5), 14081453.

(39) Tao, F.; Bernasek, S. L. Understanding Odd-Even Effects in Organic Self-Assembled Monolayers. Chem. Rev. 2007, 107 (5), $1408-1453$

(40) Cassie, A.; Baxter, S. Wettability of porous surfaces. Trans. Faraday Soc. 1944, 40, 546-551.

(41) Stephens, C. J.; Mouhamad, Y.; Meldrum, F. C.; Christenson, H. K. Epitaxy of Calcite on Mica. Cryst. Growth Des. 2010, 10 (2), 734-738.

(42) Chen, S.; Seidel, M. T.; Zewail, A. H. Atomic-scale dynamical structures of fatty acid bilayers observed by ultrafast electron crystallography. Proc. Natl. Acad. Sci. U. S. A. 2005, 102 (25), 8854.

(43) Kaganer, V. M.; Osipov, M. A.; Peterson, I. R. A molecular model for tilting phase transitions between condensed phases of Langmuir monolayers. J. Chem. Phys. 1993, 98 (4), 3512-3527.

(44) Fox, M. A.; Whitesell, J. K. Organische Chemie: Grundlagen, Mechanismen, Bioorganische Anwendungen; Spektrum Akad. Verlag, 1995.

(45) Rowland, R. S.; Taylor, R. Intermolecular nonbonded contact distances in organic crystal structures: Comparison with distances expected from van der Waals radii. J. Phys. Chem. 1996, 100 (18), 7384-7391.

(46) Duffy, D. M.; Harding, J. H. Simulation of Organic Monolayers as Templates for the Nucleation of Calcite Crystals. Langmuir 2004, 20 (18), 7630-7636. 
(47) Côté, A. S.; Darkins, R.; Duffy, D. M. Modeling Calcite Crystallization on Self-Assembled Carboxylate-Terminated Alkanethiols. J. Phys. Chem. C 2014, 118 (33), 19188-19193.

(48) Duffy, D. M.; Harding, J. H. Growth of Polar Crystal Surfaces on Ionized Organic Substrates. Langmuir 2004, 20 (18), 7637-7642.

(49) Tang, G. Q.; Morrow, N. R. Salinity, Temperature, Oil Composition, and Oil Recovery by Waterflooding. SPE Reservoir Eng. 1997, 12 (04), 269-276.

(50) Dickson, A. G.; Goyet, C. Handbook of methods for the analysis of the various parameters of the carbon dioxide system in sea water. Version 2. ORNL/CDIAC-741994. DOI: 10.2172/10107773

(51) Shi, L.; Olsson, M. H. M.; Hassenkam, T.; Stipp, S. L. S. A pHResolved View of the Low Salinity Effect in Sandstone Reservoirs. Energy Fuels 2016, 30 (7), 5346-5354.

(52) Buckley, J. S.; Wang, J. Crude oil and asphaltene characterization for prediction of wetting alteration. J. Pet. Sci. Eng. 2002, 33 (1-3), 195-202. 